\title{
LIII. The constitution of the aromatic nucleus
}

\section{S. A. Sworn B.A. Assoc. R.C.Sc.I.}

To cite this article: S. A. Sworn B.A. Assoc. R.C.Sc.I. (1889) LIII. The constitution of the aromatic nucleus, Philosophical Magazine Series 5, 28:175, 443-451, DOI: 10.1080/14786448908619890

To link to this article: http://dx.doi.org/10.1080/14786448908619890

$$
\text { 曲 Published online: } 08 \text { May } 2009 .
$$

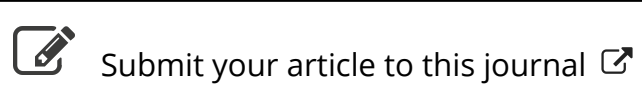

\footnotetext{
Џ Article views: 2
}

Q View related articles $₫$ 


\section{[ 443$]$}

LIII. The Constitution of the Aromatic Nucleus. By S. A. Sworn, B.A., Assoc. R.C.Sc.L., late Brackenbury Scholar of Balliol College, Oxford.

[Concluded from p. 415.]

\section{Arguments against Meyer's symbol.}

(1) BAEYER has brought forward, as an argument $B$ against Ladenburg's symbol, the fact that dihydroxyterephthalic ether (a benzene derivative) is converted by nascent hydrogen into succino-succinic ether (a hexamethylene derivative) (Ber. xix. p. 1797).

A. K. Miller and Ladenburg have each shown his deduction to be faulty (J.C. S. 1887, p. 209). (Without a single exception the facts quoted by these chemists can be as well explained by the symbol of Claus as by that of Kekulé.)

It would indeed be a serious objection to Ladenburg's symbol could it be shown that on hydrogenation the paralinkages are successiveiy split. We should thus expect to get two trimethylene rings. Facts are in opposition to such a supposition.

But this is not the only conceivable way in which the reaction may occur. A hexamethylene ring may be formed by the dissolution of one para- and two meta-linkages, the atoms being supposed to open out into a hexagonal ring (vide supra, p. 405). It is perhaps improbable that a stable meta-linkage (corresponding to ortho-linkage in Thomsen's symbol) would be severed in favour of a much weaker para-linkage. The fact, however, remains that the additive compounds can be so derived. The hexamethylene ring so obtained will differ from that derived from Thomsen's symbol in this respect-that the order of the six atoms will not be the same. This is evident from the following diagrams:-

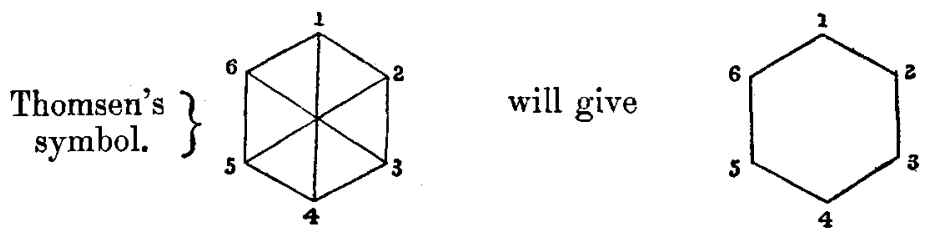


Ladenburg's symbol.

will give

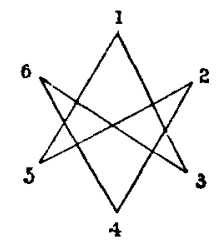

or

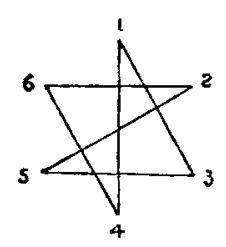

or

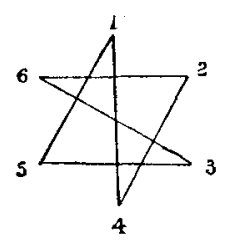

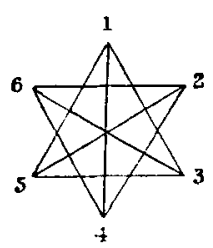

opening out to

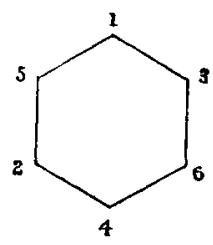

opening out to

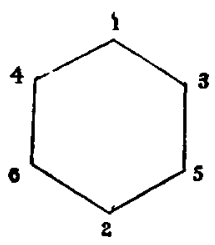

opening out to

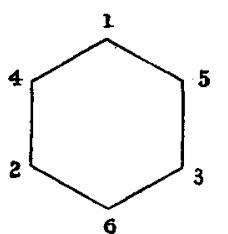

The difference may be thus defined:-

The symbol of Thomsen will give rise to a ring in which each carbon atom is bound to what were in the benzene molecule its ortho-neighbours; whereas in those derived from Ladenburg's symbol, a carbon atom would in no case be directly attached to atoms which were previously its ortho-neighbours.

The ascertained constitution of conine helps us to distinguish between these two methods of notation. Conine is undoubtedly the hexahydro-derivative of ortho-propyl pyridine. (See especially the researches of Hofmann, Ladenburg, Skraup, and Cobenzl, on conine and picolic acid, described in Pictet's "La Constitution Chimique des Alcaloz̈des Végétaux.")

Its optical activity is due to the presence of an asymmetric 
carbon atom. No exception to this rule is at present known (see especially "Dix années dans l'histoire d'une théorie," by Van't Hoff). When derived from Ladenburg's symbol, the formulæ for conine cannot possess an asymmetric carbon atom. This is evident from the following symbols :-

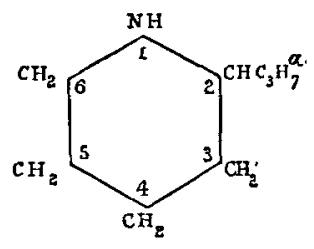

From Thomsen's symbol.
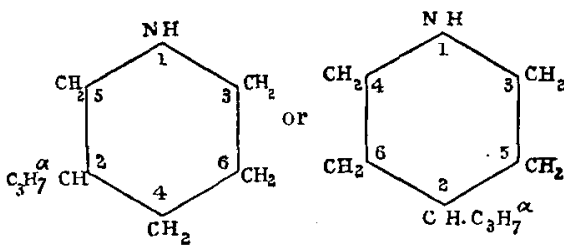

From Ladenburg's symbol.

Moreover Ladenburg's theory would indicate the possible existence of two position isomers derived from $\alpha$-allyl pyridine.

The properties of conine, when thus considered, afford direct evidence that pyridine is to be represented on Thomsen's type and not on Ladenburg's. This deduction is confirmed by the fact that Knorr and Antrick's researches (vide suprì, p.414) prove by direct synthesis the existence of ortho-linkage between the nitrogen and the $\alpha-, \beta$-, and $\gamma$-carbon atoms in the pyridine nucleus of $\boldsymbol{\gamma}$-oxy-quinaldine, thus :-

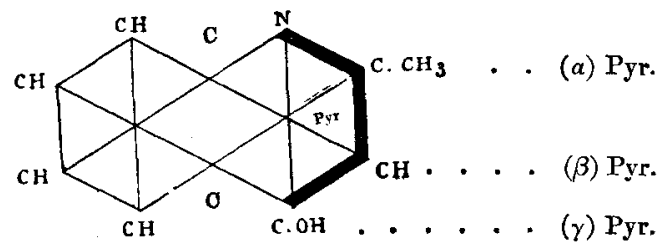

(The proved ortho-linkages in thick lines.)

(2) It is commonly stated that Ladenburg's symbol will not account for the conjugated derivatives of benzene. This is not altogether true, although there are difficulties which do not exist in the case of Thomsen's symbol.

In the case, for example, of naphthalene it is necessary to sever two para-linkages and to set up an ortho-linkage in each aromatic nucleus (II.). The symbol (III.) which Meyer gives is complicated by the improbable supposition that the atoms 3 and $3^{\prime}, 4$ and $4^{\prime}$, are directly linked together, and by the fact that phenanthrene cannot be similurly represented (vide infrà).

Phil. Mag. S. 5. Vol. 28. No. 175. Dec. 1889. 2 L 


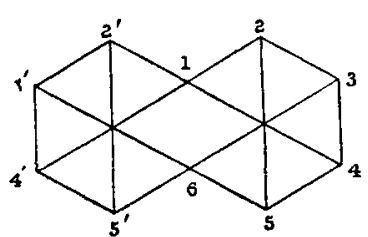

From Thomsen's symbol.

I,

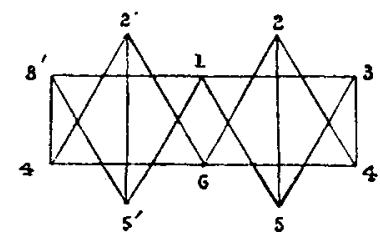

From Ladenburg's symbol (octahedral).

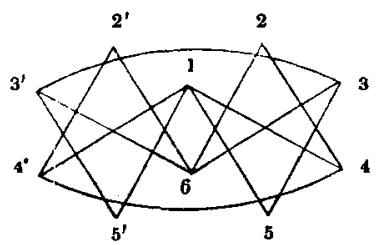

Meyer's symbol.

III.

Naphthalene as thus constituted (II.) could hardly be said to consist of two aromatic nuclei. That it does consist of two such nuclei is evident from the fact that, like benzene, it has an abnormally low molecular volume, and gives substitution products by direct nitration and sulphonation. Moreover, in the formation of these derivatives the action appears to follow as closely as possible the laws of substitution which hold for benzene derivatives. Hartley found the absorption of the ultra-violet rays characteristic of benzene to be even greater in the cases of naphthalene, anthracene, and phenanthrene.

The same difficulties hold with regard to the other conjugated bodies. Unless ortho-linkage is set up it is difficult to account for the ascertained constitution of phenanthrene, more especially its formation from stilbene.

I may quote the formulæ which might be assigned to phenanthrene and pyrene.

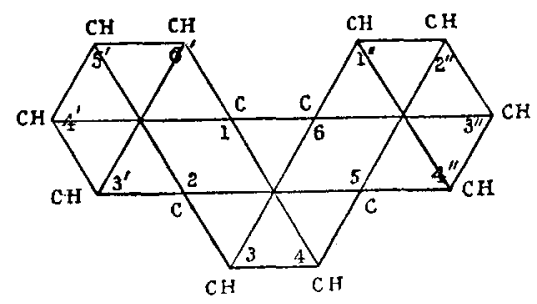

Phenanthrene, $\mathrm{C}_{14} \mathrm{H}_{10}$ (from Thomsen's symbol).

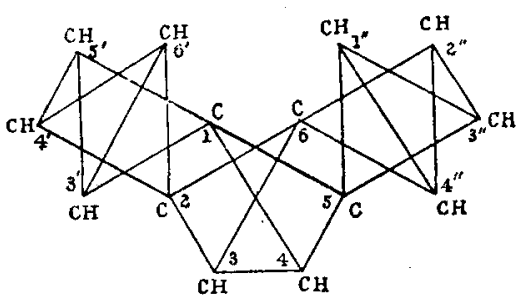

Phenanthrene, $\mathrm{C}_{14} \mathrm{H}_{10}$ (from Meyer's symbol). 


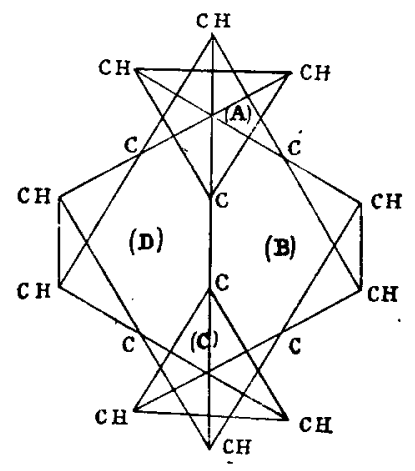

Pyrene, $\mathrm{C}_{16} \mathrm{H}_{10}$ (from Meyer's symbol).
Compare with p. 410 .

(3) It is generally admitted that closed chains of more than six atoms do not exist. If this be so, it is difficult to account for the constitution of fluorene on Ladenburg's theory, as it is then necessary to assume the existence of a closed chain of seven carbon atoms. In the formulation of this body from Thomsen's symbol this ring consists of five carbon atoms only. The relationship of fuorene to phenanthrene, through diphenylene ketone and diphenic acid, proves it to be a di-orthocompound. The argument is evident from the following symbols :-

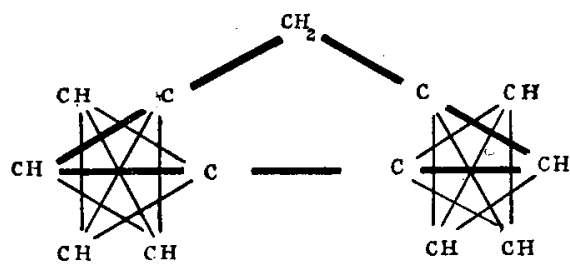

Fluorene, $\mathrm{C}_{3} \mathrm{H}_{10}$ (on Ladenburg's symbol).

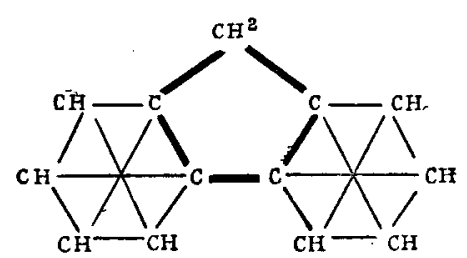

Fluorene, $\mathrm{C}_{13} \mathrm{H}_{r_{0}}$ (on Thomsen's symbol).

In this connexion I may quote the following passage from Watts' 'Dictionary of Chemistry' (new edition, i. p. 300) :"Ortho-compounds readily give rise to products of condensation in which the side chains may be supposed to be joined in the form of a ring; this tendency is observed to some extent in the para-series but not at all in the meta-series."

(4) The analogies between the ortho- and para-derivatives of benzene as opposed to the meta- have been cited by Koerner (J. C. S.1876, i. p. 240) and by Lellmann (Ber. xvii. 
p. 2720) in favour of ortho- and para-linkage. It must be confessed that these arguments dejend upon hypothetical views as to the cause of such analogies, and are therefore not very conclusive. Stuart has similarly brought forward the results of his experiments on the benzolmalonic acids (J.C.S. 1886 , p. 357) in support of Kekulés formula-a formula which is at variance with so many facts.

\section{Thomsen's Symbol.}

The preceding discussion affects merely the nature of the atomic linkage, and shows that the diagonal symbol of Claus is alone consistent with all the facts. The argument is not merely based on hypothetical analogies between benzene and pyridine derivatives. The independent consideration of these groups of bodies clearly shows that they must be formulated on the same type.

(1) Thomsen's symbol is a development of that of Claus, but the positions of the hydrogen atoms are not considered.

It is most natural to suppose that any given hydrogen atom is attached to its carbon atom, in such a manner that the direction of the valency falls within the solid angle formed by the three other valencies which unite that carbon atom to its ortho- and para- neighbours. If, for example, we assume that this valency is equally inclined to the other three, it will make an angle of $148^{\circ} 36^{\prime}$ with them (or $31^{\circ} 24^{\prime}$ with the diagonal of the octahedron).

But whatever may be the true angle of deviation it is evident that, whilst the meta- and ortho-carbon atoms are equidistant, the meta-hydrogen atoms (or rather their mean positions) would be closer together than the ortho-.

If the configuration of the benzene molecule as a whole were octahedral, we should expect the crystals of benzene to belong to the regular system. But they are rhombic. Schrauff has considered this point (Wiedemann's Annal. Neve Folge, xxxi. p. 540), but the positions which he assigns to the hydrogen atoms give a symbol which would indicate the existence of two isomeric mono-substitution derivatives.

Further, any space formula for benzene, which represents all the atoms in one plane (see Claus, Ber. xx. p. 1425), would lead us to suppose that benzene would crystallize in the hexagonal system.

(2) The development of Thomsen's symbol which I have proposed in no way affects the questions which were previously discussed (I. and II.).

It affords a basis for an explanation of the so-called para- 
and meta-laws of substitution (see Armstrong J. C. S. li. p. 259).

(a) Let us consider the continued action of sulphuric acid upon benzene. The sulphonic group first introduced is itself sulphonized, and for the moment an unstable body (B) is formed. This compound gives off a molecule of water, the hydroxyl $(n)$ being eliminated with one of the ortho- or metahydrogen atoms $\left(o_{4} o_{6} m_{1} m_{3}\right)$. Simultaneously with this change the two sulphonic groupings ( $a$ and $b$ ) become disunited, and $(b)$ takes the place of the eliminated hydrogen atom. As in a large number of such molecules, the hydroxyl (n) will be more often in closer proximity to a meta- than to an ortho-hydrogen atom, and always closer to one of these than to the para-hydrogen atom $(p)$, we shall get the formation of meta- and ortho- to the exclusion of para-benzenedisulphonic acid, and of these the meta will be the chief product. These changes may be graphically represented thus:-

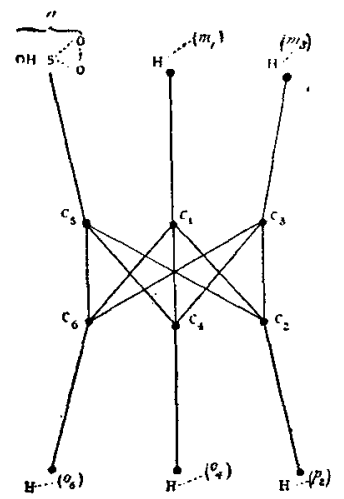

(Elevation.)

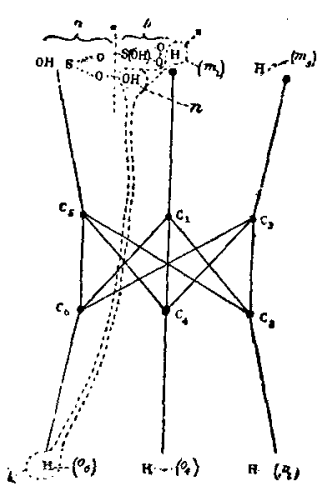

Intermediate Body (B).

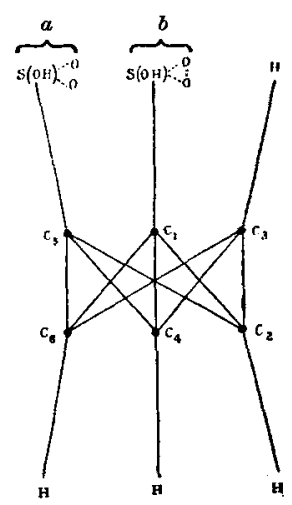

Benzene metadi-sulphonic acid.

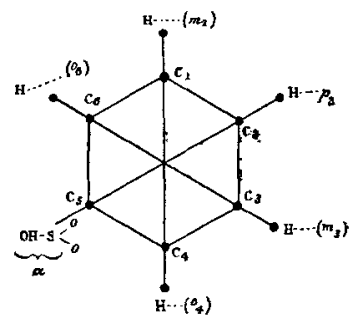

(Plan).

Benzene sulphonic acid, $\mathrm{C}_{6} \mathrm{H}_{5} \mathrm{SO}_{3} \mathrm{H}$. 
(b) This explanation is dependent upon the nature of the radical first introduced. If this radical has no tendeney to form addition products, the further substitution must be effected by the momentary dissolution and re-establishment of one of those aromatic linkages which attach its ortho- and pari- neighbours to the carbon atom whose hydrogen is already displaced. (This explanation is admitted for the monosubstitution derivatives.)

Meta-derivatives are not obtained because there is no metalinkage, and para-derivatives are formed in greater quantity than ortho- because the para- is less stable than the ortholinkage. The formation of $o-$ and $p$-dibromobenzenes, by the direct bromination of benzene, may be thus represented. (See page 451.)

(c) In a similar development of Meyer's symbol the orthohydrogen atoms would be nearest to one another, and similar arguments would lead us to ortho- and para-laws, and the formation in each case of meta-compounds in small quantity.

Attempts have been made by Schiff (Annalen, ccxx. p. 303), by Lossen (Annalen, cexxv; p. 119), by Horstmann (Ber. xx. p. 766 ; xxi. p. 2211), by Brühl (Annalen, cc. p. 228), by Thomsen (Therm. Cnt. Iv. pp. 61, 273), and others to determine the constitution of benzene from its physical constants. The calculations of these chemists presuppose the existence of paraffinoid and olefinoid linkages alone, and lead to conflicting results. Moreover they are based on so-called "laws," such as that of Kopp, the general application of which (in the case of molecular volumes) has been disproved by numerous researches.

It is certainly true that the linkages in aromatic compounds are not directly comparable in such a manner with those in fatty bodies; and it is therefore impossible to make use of arguments based upon the measurements of specific volumes and refractive indices and apon thermochemical data, until some quantitative connexion has been made out.

In a future paper I hope to bring forward some calculations based upon space formula and made with the object of advancing this question. 
of the Aromatic Nucleus.
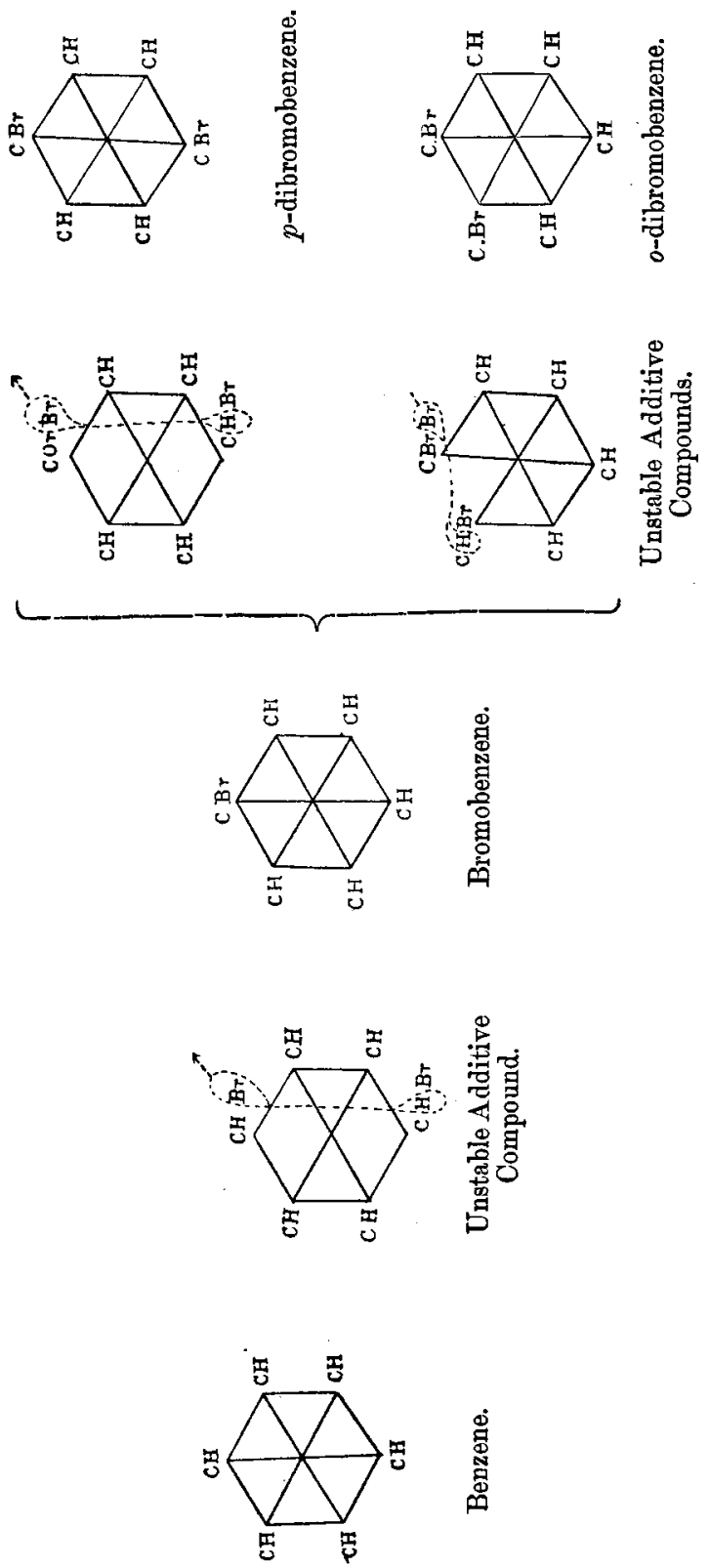